\title{
FLORIDABLANCA, ARANDA, GODOY Y EL «PARTIDO DE LA REINA»: LA INFLUENCIA POLÍTICA DE Ma LUISA DE PARMA EN LOS PRIMEROS GOBIERNOS DE CARLOS IV (1788-1796)
}

\author{
Antonio Calvo Maturana* \\ Universidad de Alicante
}

... por lo que toca al Rey y su Mujer, a si es buena o no, el Rey es quien debe responder, yo por mi parte digo que cumplo como buena mujer de mi marido y del Rey, que son uno mismo en una pieza, que hago cuanto alcanzan mis luces, las que quisiera fueran según mis deseos...

(María Luisa a Godoy. Aranjuez, 26 de Marzo de 1800²)

Fecha de recepción: noviembre de 2009

Fecha de aprobación: febrero de 2010

Existe un total consenso historiográfico sobre la influencia política que tuvo María Luisa de Parma mientras reinó su marido Carlos IV (también como princesa de Asturias y reina madre exiliada). Los prejuicios con los que ha cargado esta reina, y tantas otras de su época, la han dejado huérfana de todo intento de análisis serio, reduciendo su influencia a la debilidad de su esposo y a sus intrigas «mujeriles» ${ }^{2}$.

\footnotetext{
* Adscrito al proyecto I+D: «De la corte ilustrada a las elecciones democráticas: mujeres, participación política y espacio público en España» (HAR2008 - 01558/HIST).

1. Pereyra, Carlos: Cartas confidenciales de la reina María Luisa y de Don Manuel Godoy, Madrid, 1935, p. 275.

2. Tema del que me he ocupado en profundidad (María Luisa de Parma: reina de España, esclava del mito, Granada, 2007).
} 
En consecuencia, apenas se han investigado los recursos de la reina para ejercer ese poder dentro de la lógica cortesana de finales del siglo XVIII y principios del XIX. Incluso suponiendo - discutible suposición, por cierto- que la parmesana hubiese gozado de un poder omnímodo y hubiese gobernado a su antojo, la Corte tenía sus resortes políticos y sus propios canales de poder para hacer efectivo el deseo de los reyes. De una correcta utilización de estos recursos cortesanos dependía la fuerza real de los monarcas. Pronto veremos cómo Carlos y $\mathrm{M}^{\mathrm{a}}$ Luisa hacían política y se desenvolvían con habilidad en su entorno, que no era otro que la Corte; una Corte con un ceremonial más relajado que el de antaño ${ }^{3}$, pero que mantuvo todos los mecanismos que facilitaban la política del secret du Roi.

Este trabajo no se ocupa únicamente de la reina (de ahí su título). Las circunstancias historiográficas por todos conocidas harán que, según revisemos el papel político de María Luisa de Parma, vayamos matizando alguno de los clichés que comúnmente han acompañado a Carlos III, Carlos IV, Floridablanca, Aranda y Godoy.

Este repaso de los primeros gobiernos de Carlos IV desde el punto de vista de la consorte regia tratará de hacerse en buena parte con fuentes poco o nada conocidas. Entre todas, destaco dos. En primer lugar, cierta correspondencia entre estos personajes, contenida en el Archivo Histórico Nacional. En segundo lugar, pero no menos importante, la correspondencia del embajador inglés en Madrid con el Foreign Office. Los informes de la embajada inglesa -además del doble valor de estar prácticamente inéditos y de ser testimonios de testigos directos- tienen una tercera virtud. Mientras que el ruso Zinoviev y el francés Alquier hacían de la política española un entramado de intrigas de alcoba, los británicos Liston, Edem y Fitzherbert ofrecían a Londres una perspectiva mucho más profesional (esto es, más cercana a nuestra concepción contemporánea de lo que tiene que ser un embajador) y menos mitológica de lo que estaba ocurriendo en la Corte. Sin embargo, los embajadores que se regodearon en la reina caprichosa y ninfómana han sido citados repetidamente, mientras que no parece que nadie haya tenido ganas de ir a los londinenses Kew Gardens a «escuchar» los testimonios ingleses (a los que no se puede acusar de proespañoles precisamente).

\section{EL PRÍNCIPE Y LA PRINCESA DE ASTURIAS ENTRE FLORIDABLANCA Y ARANDA}

Aunque suponga anticiparse al marco cronológico propuesto, quiero hacer una pequeña reflexión sobre las inquietudes políticas de Carlos y $\mathrm{M}^{\mathrm{a}}$ Luisa como príncipes de Asturias, ya que nos ayudará a comprender sus decisiones a partir de 1788. El recelo de ambos a Floridablanca y la afinidad con Aranda sólo se ha documentado a raíz del célebre episodio de 1781, aquel Plan de Gobierno que los príncipes solicitaron al

3. Ver dos trabajos de VÁzQuez GeSTAL, Pablo: ««Non dialettica, non metafisica...». La Corte y la cultura cortesana en la España del siglo XVIII», Reales Sitios, XLIII, 169 (2006), pp. 50-69; y, sobre todo, «La Corte de Carlos IV y la reina María Luisa (1788-1808)», en ENCISO RECIO, L.M. (dir.): La Nación recobrada. La España de 1808 y Castilla y León, Valladolid, Junta de Castilla y León, 2008, pp. 37-53. 
aragonés, descubierto por Carlos III. En la carta que Carlos envió a Aranda el 19 de marzo de 1781 hablaba de «lo poco que hay que contar con los ministros que ahora hay»; en otra de julio del mismo año se solidarizaba con las quejas del noble aragonés sobre su rival: «bien veo lo que te pasa con Moñino, pero qué se ha de hacer sino tener paciencia» ${ }^{4}$.

Pocos años antes, en 1778, pudo surgir el principio de esa desconfianza de Carlos hacia el ministro de su padre. Floridablanca informaba al príncipe de Asturias de las negociaciones y la posterior guerra contra Inglaterra, pero un día faltó la carta y Carlos debió enfadarse. La misiva de Floridablanca, en respuesta al enfado del príncipe, merece ser leída prácticamente completa por lo inmediatamente dicho y porque desmiente el pretendido desinterés del futuro Carlos IV por los asuntos políticos:

«Serenísimo señor, empiezo pidiendo humildemente perdón a V.A. de la omisión involuntaria, en que incurrí dejando de escribir el lunes. En aquel día no tuvimos noticia alguna (...) Este fue el motivo de no escribir, pues bien, cierto es que habiendo la menor novedad, no hubiera dejado de avisarla, ni el Rey de mandármelo como acostumbra. Sin embargo en los días de correo obedeceré como es justo lo que V.A. quiere, diciendo lo que ocurra; y si nada ocurre, diré que no hay novedad. Si entre semana hubiere algo de nuevo lo avisaré. Pero permítame V.A. que postrado a sus reales pies le confiese mi aflicción, cuando leo en su carta que pudiera haberme incomodado en escribir, y cuando me amenaza con su real desgracia si falto otra vez. Quien ha perdido su salud en treinta años de servicio, y quien ahora no sosiega de día ni de noche por servir al rey, a V.A. y a la Patria, no sólo no se incomodará en escribir a V.A., sino que por darle gusto perderá la incomodidad, la salud y la vida. Si lo amase y sirviese a Dios, como amo a V.A. y como deseo servirle podría esperar verme entre los santos canonizados. Esto no obstante podré tener alguna falta involuntaria por inadvertencia, y en tal caso pido encarecidamente a V.A. que me la advierta para mi corrección antes de negarme su gracia, sin la cual nada quiero, ni me importan unos encargos que no he buscado ni apetezco. Ruego ahora a Dios guarde la vida de V.A. millares de años» ${ }^{5}$.

Sabemos por el mismo legajo que Carlos III informaba puntualmente a su hijo ( «Su Majestad quiere que le participe a V.A. de todo lo que ocurre con la mayor reserva» ${ }^{6}$ ) y que este opinaba («el rey está en que conviene tomar partido como V.A. dice, si la Inglaterra no nos hace justicia; pero la dificultad está en asegurarse de la Francia» ${ }^{7}$ ).

No es menos cierto que desde muy pronto se notó también el interés de María Luisa en los problemas de Estado. En la carta ya referida a Aranda de 1781, el entonces príncipe dejó constancia de que ella estaba junto a él cuando escribía («mi mujer, que

\footnotetext{
4. El príncipe Carlos a Floridablanca. El Pardo, 19 de Marzo de 1781. Archivo Histórico Nacional, Estado, legajo 4823-1.

5. Floridablanca al príncipe Carlos. San Ildefonso, 25 de Septiembre de 1778. A.H.N., Estado, 1.2453.

6. Floridablanca al príncipe Carlos. San Ildefonso, 10 de agosto de 1778. Ibidem.

7. Floridablanca al príncipe Carlos. San Ildefonso, 13 de agosto de 1778. Ibid.
} 
está aquí presente, te encarga lo mismo» ${ }^{8}$ ). Destapada la pseudo-conspiración entre Aranda y los príncipes, el mismo Carlos III responsabilizó a su nuera de las intrigas de su hijo en una interesante carta al príncipe Carlos de la que sólo rescataré la frase acusatoria:

«Por último, quiero hacerte otra observación importante: las mujeres son naturalmente débiles y ligeras, carecen de instrucción y acostumbran mirar las cosas superficialmente, de que resulta tomar incautamente las impresiones que otras gentes con sus miras y fines particulares las quieren dar»?.

Más adelante volveré sobre este episodio al hablar del ascenso de Aranda, destapando el papel de $\mathrm{M}^{\mathrm{a}}$ Luisa como mediadora entre el conde y el rey en los años previos a 1792. Quedémonos por ahora en 1788. Aunque nunca está de más desmentir la supuesta abulia de Carlos IV, digamos que no es incompatible con la evidente coincidencia de todas las fuentes en la influencia política de su esposa. Días después de la muerte de Carlos III, el embajador francés, La Vauyugon, sabía que la parmesana estaba llamada a tener un papel fundamental en la política del reinado:

«La confianza sin reservas que el Señor Príncipe de Asturias demostraba constantemente en relación a la Señora Princesa anunciaba hace mucho, Señor, todo el alcance del poder que ella tendría sobre él cuando alcanzase el trono. Su diligencia en admitirla desde el primer día de su reinado en los trabajos de su Ministerio y de iniciarla en todos los detalles de los trabajos del Gobierno justifica esta opinión; por lo tanto, es sobre la absoluta preponderancia de la reina sobre la que se deben establecer los nuevos cálculos de la política relativa a España» ${ }^{11}$.

\section{FLORIDABLANCA Y LA CONTINUIDAD DE LA HERENCIA POLÍTICA DE CARLOS III}

Tanto Carlos III como su mano derecha, el conde de Floridablanca, se habían granjeado cierto prestigio internacional en los últimos años del reinado de aquel. Sobre este último, los embajadores solían coincidir tanto en su buen hacer como en su tremenda influencia política. Moñino había creado a su alrededor una red clientelar muy poderosa, y había conseguido anular políticamente a su gran rival: el conde de Aranda. Según escribió el inglés Robert Liston a mediados de 1788, el ministro controlaba todos los asuntos de Estado y «su poder e influencia son ilimitados ahora mismo en este gobierno ${ }^{12}$. Pocos días después, el sustituto de Liston en la embajada, William Edem coincidía en ver en Moñino a alguien todopoderoso y digno de respeto:

8. Esta intimidad se mantendrá en el futuro. En múltiples ocasiones, Carlos estará presente cuando su esposa escriba a Godoy y hará apreciaciones al «amigo Manuel» que María Luisa transcribirá.

9. EGIDO, Teófanes: Carlos IV, Madrid, 2002, p. 44.

10. Las traducciones de la correspondencia diplomática británica y francesa son del autor.

11. La Vauyugon à Montmorin. Madrid, le 31 Decembre 1788. Archives des Affaires Étrangères, Correspondance politique. Espagne, 625.

12. Liston to Leeds. Aranjuez, June $6^{\text {th }}$ 1788. National Archives (Londres), Foreign Office, 72/12. 
«La única manera de obtener confianza con Floridablanca es mostrando confianza en él. Su poder e influencia son ahora mismo insalvables en este gobierno. Y aunque su actitud no es tan atenta y conciliadora como la de otros primeros ministros con los que he negociado, tengo motivos para pensar que es justo y honorable». ${ }^{13}$

El cambio de monarca abrió un periodo de desconcierto en las embajadas. Los ministros extranjeros se preguntaban por la línea política que seguiría Carlos IV. Leamos dos párrafos recibidos respectivamente en París y en Londres, en ambos encontramos el peso de María Luisa de Parma en la decisión final del rey de mantener a Moñino:

«La mayoría de los que se creían en gracia con la Señora princesa de Asturias veían la muerte de Carlos III como el término del crédito de los principales depositarios de su confianza, pero el primer acto del nuevo rey fue confirmar los ministros de su padre en todos sus departamentos. El Señor Floridablanca, del cual los especuladores esperaban una rápida caída, ha recibido por parte de Sus Majestades Católicas las pruebas más halagadoras de su satisfacción por sus servicios y de su estima por sus talentos. Es cierto que la Señora princesa de Asturias había demostrado una distancia muy acentuada hacia él, la cual en diversas ocasiones no había disimulado; pero parece que [Floridablanca] ha logrado disipar estas nubes, y sustituir las cautelas que sus enemigos habían inspirado anteriormente por una imagen positiva de su probidad y su clarividencia» ${ }^{14}$.

«En los asuntos del nuevo reinado, según parece, la influencia de la reina es ilimitada y activa. El conde de Floridablanca continua siendo tratado con plena confianza, y me alegra saber que en numerosas ocasiones ha sido consultado por Sus Majestades antes de dar una orden a los otros ministros» ${ }^{15}$.

Floridablanca se mantenía en el poder, pero tanto Edem como La Vauyugon coincidían en el gran número de enemigos que tenía en la Corte y en su absoluta dependencia de la confianza de los reyes; especialmente del favor de la reina. En 1792, cuando Moñino caiga en desgracia, la idea más extendida será que María Luisa nunca quiso al ministro y que este había tenido su gran apoyo en Carlos IV.

En las fuentes encontramos una diferencia de criterios entre el rey y su esposa. En mi opinión, es más probable que estas disensiones recogidas por los diplomáticos hayan de interpretarse como un arma política de Carlos y María Luisa que como diferencias de un matrimonio mal avenido. En el siguiente apartado intentaremos demostrarlo poniendo como ejemplo la política exterior de la Monarquía Hispánica.

ENTRE INGLATERRA Y FRANCIA: EL JUEGO DIPLOMÁTICO DE LA PAREJA REAL

Una vez firmada la paz con Inglaterra en 1783, el conde de Floridablanca quiso hacer de la neutralidad la bandera de la política exterior española. Esta nueva política

13. Edem to Leeds. Aranjuez, June $10^{\text {th }} 1788$. N.A., F.O., 72/12.

14. La Vauyugon à Montmorin. Madrid, le 31 Décembre 1788. A.A.E., Correspondance politique. Espagne, 625.

15. Edem to Leeds. Madrid, $29^{\text {th }}$ December 1788. N.A., F.O., 72/13. 
se fundamentaba, sobre todo, en una cierta independencia respecto a los dos grandes poderes y en la búsqueda de una tercera vía que aglutinase a los Estados de segunda fila (si es que potencias como Prusia, Rusia, el Imperio Austríaco o la propia Monarquía Hispánica merecían esta denominación).

Si bien desesperaba a los ingleses con la promesa de un tratado comercial que nunca se concretaba y a los franceses con una cierta arrogancia que Montmorin (su homólogo francés) no dejaba de percibir, hay que reconocerle a Floridablanca que consiguió que en diciembre de 1788, tanto ingleses como franceses quisiesen que fuera ratificado en el cargo por el nuevo rey. Así lo hacía ver -con reservas- La Vauyugon en París...

«Estoy convencido, Señor, que vos pensáis como yo que es deseable para la Casa de Borbón que él [Floridablanca] conserve la confianza principal de Sus Majestades Católicas. Su carácter impetuoso tiene inconvenientes que no escapan a quienes han tenido la ocasión de negociar con él; pero en él la más rara sagacidad se une a su mucha rectitud, y aunque no sienta una inclinación especial por la nación francesa, e incluso comparta, hasta cierto punto, la envidia que nuestra superioridad en muchos aspectos inspira a los extranjeros, sobre todo a los españoles, sus principios sobre la unión de la Casa de Borbón son invariables, y no cabe duda de que contribuirá útilmente a mantener y a desarrollar aquellos principios anunciados por sus Majestades Católicas» ${ }^{16}$.

... y así Edem - que acababa de sustituir a Liston como embajador inglés en Madrid-recién fallecido Carlos III:

«El acontecimiento que acaba de producirse, debe ser considerado en cada Corte europea como interesante e importante. El carácter del anterior rey de España le obligaba ineludiblemente a participar con Francia en todas las guerras en las que esta entrara. Pero ciertamente, el conde de Floridablanca ha demostrado durante la misión aquí del Señor Liston, y más desde mi llegada, un fuerte deseo de llevar a esta Corte a una línea política más digna e independiente» ${ }^{17}$.

Fueron años de duda en la corte madrileña. El conflicto de Nootka-Sound acabaría demostrando ${ }^{18}$ que Inglaterra, por sus intereses en América, era un aliado imposible y que la tercera vía diplomática era un fracaso. La respuesta seguía siendo Francia ${ }^{19}$, pero hasta 1796 se deshojó la margarita del acercamiento o no a un gobierno republicano (con guerra frontal incluida). En definitiva, por una u otra circunstancia, la política internacional de Carlos IV, en el trienio en el que gobernó Floridablanca, fue básicamente una continuación de la de su padre, algo que se pudo observar tanto antes como

16. La Vauyugon à Montmorin. Madrid, le 31 Décembre 1788. A.A.E., Correspondance politique. Espagne, 625.

17. Edem to Leeds. Madrid, $15^{\text {th }}$ December 1788. N.A., F.O., 72/13.

18. Ver mi artículo: «Génesis del II Imperio Británico y ocaso del universalismo español: la doble vertiente del conflicto de Nootka (1790)», Hispania, LXVIII, 228 (2008), pp. 151-192.

19. Ver: LA PARRA LÓPEZ, Emilio: La alianza de Godoy con los revolucionarios (España y Francia a fines del siglo XVIII), Madrid, CSIC, 1992. 
después de los condicionantes de julio de 1789 (toma de la Bastilla) y de 1790 (año álgido de la crisis de Nootka).

El nuevo rey -«de natural sensibilidad y ardiente carácter»- era diferente a su testarudo antecesor: «no parece que tenga predilección por la nación francesa», pero «por otra parte la influencia de la Reina sobre él es infranqueable y es difícil de prever a qué Corte se dirigirá ${ }^{20}$. Edem observaba en Carlos un mayor desapego a la política de los Pactos de Familia y apreciaba en él la suficiente confianza en el imperio español como para mantener una línea independiente ${ }^{21}$. En cuanto a María Luisa, al diplomático no le cabía duda de que - por afinidad familiar- su predilección se dirigía más a Francia y al Imperio que a Inglaterra ${ }^{22}$. La reina, además, era una defensora de las garantías que ofrecía la «conexión borbónica».

Sucesivamente, el plenipotenciario confirmó todos estos apuntes: la influencia de la consorte «en los asuntos del nuevo reinado» y la «feliz» permanencia del conde en su puesto ${ }^{23}$; el nuevo monarca iba a adoptar el sistema político heredado. El Pacto de Familia se definía como «una alianza que España, por buena fe y otros motivos, tiene que respetar y cultivar, pero sin afectar a su independencia». La frialdad hacia Francia era presumible y los deseos de mejorar las relaciones con Inglaterra parecían pasar de las buenas palabras. Floridablanca no se cansaba de decir que España era neutral y que sólo intervendría en los conflictos como árbitro ${ }^{24}$, nunca como aliado secundario de una potencia que la condujese a una guerra que no le interesaba ${ }^{25}$.

Un curioso encuentro con Carlos IV daba nuevas esperanzas al plenipotenciario y nos ofrece un didáctico episodio de la manera de hacer política en aquella Corte:

«Durante la audiencia del pasado viernes, mientras la reina de España estaba hablando al círculo de ministros extranjeros, Su Católica Majestad me invitó a retirarme a una pequeña distancia del resto, y en voz baja, pero en el tono más cordial, se expresó en términos de particular afecto acerca del rey mi soberano, en ocasión del informe de la salud de $\mathrm{Su}$ Majestad que había recibido del marqués del Campo» ${ }^{26}$.

Esta conversación clandestina entre el rey y Edem, a espaldas de María Luisa, puede dar lugar a varias interpretaciones. La primera de ellas, la tradicional, el miedo de Carlos IV a contradecir a su irritable esposa. Punto de vista que no es incompatible con que el rey, por el medio que fuese, acabase imponiendo su criterio cuando era necesario. Ya que «todo vale» en lo que se refiere a la reina parmesana, no tienen por

20. Edem to Leeds. Madrid, December 15 th 1788. N.A., F.O., 72/13.

21. Edem to Leeds. Madrid, February $9^{\text {th }} 1789$. N.A., F.O., $72 / 14$.

22. Se rumoreaban las intenciones de la reina de casar a una de sus hijas con el Delfín. Las relaciones familiares de María Luisa de Parma con el Imperio provienen de dos matrimonios: el de su malograda hermana Isabel de Borbón-Parma con José II y el del futuro Leopoldo II con su prima María Luisa de Borbón (hija de Carlos III).

23. Edem to Leeds. Madrid, December 29 ${ }^{\text {th }} 1788$. N.A., F.O., 72/13.

24. Edem to Leeds. Madrid, January $16^{\text {th }} 1789$. N.A., F.O., $72 / 14$.

25. Edem to Leeds. Madrid, February $2^{\text {nd }} 1789$. N.A., F.O., 72/14.

26. Edem to Leeds. Madrid, March $16^{\text {th }} 1789$. N.A., F.O., $72 / 14$. 
qué estar de más otros dos puntos de vista menos recurrentes y más alejados de esos lugares comunes de los que tanto ha abusado la historiografía.

En primer lugar, se puede intuir, así por las constantes tensiones y distensiones, como por la innumerable serie de vagas promesas que dará Floridablanca en estos años a todas las legaciones (incluida la exiliada francesa tras 1789), que la línea política del secretario de Estado y su rey era levantar una serie de cortinas de humo para que todo siguiese como estaba el mayor tiempo posible. Unos días antes, Edem había escrito sobre la diferente opinión de la pareja real:

«Sigo pensando que la disposición de Su Majestad Católica se inclina hacia nosotros. Lo creo así (...) por lo que he podido recoger del ministro español y por el tratamiento de Su Majestad Católica hacia mí, y por pequeñas circunstancias difíciles de detallar. No pienso de ninguna forma lo mismo de la reina de España. Sus atenciones son, en todos los aspectos, solícitas y conciliadoras en extremo, pero se supone su predilección por la corte de Versalles, y ciertamente tiene un alto concepto de la importancia de una conexión borbónica» ${ }^{27}$.

Carlos volvió a dirigirse a un embajador inglés en privado en julio de 1790, en esta ocasión para transmitirle personalmente su satisfacción por la recién firmada declaración derivada del conflicto de Nootka; la que dijo considerar un triunfo de «la perfecta armonía y buen entendimiento cuyo mantenimiento con la corona de Gran Bretaña era su deseo constante». El embajador hacía ver a su ministerio lo extraordinario de este lance: «Supongo que Su Gracia es consciente de que es extremadamente inusual para Su Católica Majestad conversar con los ministros extranjeros de cualquier tema político ${ }^{28}$. Recién firmado el Tratado de El Escorial, el rey volvió a hablar con el inglés Alleyne Fitzherbert, algo que podía despertar recelos en el resto de embajadores:

«Ayer, Su Majestad Católica, cuando le hice la Corte en su Levèe, deseaba especialmente que le asegurase a Su Majestad con vehemencia la viva satisfacción que sintió por la feliz conclusión de este importante asunto, además de su intenso deseo de convertir la restauración de la armonía entre las dos coronas en una sólida e íntima conexión amistosa.

Es posible que esta conversación dé lugar a especulaciones en las diferentes cortes de Europa, puesto que ha llegado a oídos de muchos ministros extranjeros, y Su Majestad Católica se expresó sobre lo dicho arriba con su usual franqueza y en los más cálidos términos de cordialidad. De hecho, tengo motivos para creer que sus expresiones fueron totalmente sinceras, y que esta Corte procederá con la mejor disposición en la negociación para el proyecto de alianza con Gran Bretaña tan pronto como hayan recibido alguna prueba satisfactoria por nuestra parte del desarme naval: un hecho que evidentemente les interesa mucho» ${ }^{29}$.

La reina hacía con los franceses la misma labor que su esposo con los ingleses: amistad y aparente confidencialidad (si bien, en este caso, la cercanía era bastante más evidente que aparente). Durante su estancia en España, La Vauyugon tuvo una estrecha

27. Edem to Leeds. Madrid, March $9^{\text {th }} 1789$. N.A., F.O., 72/14.

28. Fitzherbert to Leeds. Madrid, July $7^{\text {th }} 1790$. N.A., F.O., 72/20.

29. Fitzherbert to Leeds. Escorial, November $22^{\text {nd }} 1790$. N.A., F.O., 72/20. 
relación con la parmesana. Meses antes del encuentro Carlos IV-Edem, María Luisa se había dirigido al embajador francés asegurándole sus inclinaciones hacia Francia:

«Enseguida, la reina se acercó a mí y me dijo: «Acabáis de escuchar las pruebas de que el Rey no lo necesita porque esos sentimientos existen naturalmente en su persona; pero si no estuviese tan penetrado por ellos como está, me tocaría a mí inspirarlos»»»30.

Así $\mathrm{M}^{\mathrm{a}}$ Luisa se convertía en la gran esperanza del embajador francés, quien en la interesante carta de 31-12-1788 que seguimos citando- afirmaba que: «hasta el momento, ella ha desarrollado todas las disposiciones que nos permiten suponer que intentará reforzar los lazos por la gloria de la casa de Borbón» ${ }^{31}$. La legación inglesa miraba con recelo las entrevistas del duque de la Vauyugon con Floridablanca, pero consideraba «más reseñable, la asidua corte que hace a la reina de España (...) sin mostrar la misma atención diligente hacia el rey» ${ }^{32}$.

Aun reconociendo a cada uno un pensamiento político propio, no tiene mucho sentido que el rey y la reina tuviesen dos concepciones tan antagónicas de lo que convenía a su corona en materia de asuntos exteriores; ¿no se repartirían los papeles con Francia e Inglaterra para excusar así la falta de definición política?; o puede que el rey se limitase a ser amable con todos los miembros de la Corte y que la reina transmitiese las decisiones. En estos reportes diplomáticos encontramos a la María Luisa más conocida, la dama cortesana que habla con los embajadores, que supuestamente convence a su marido y que asiste a las reuniones con sus ministros y consejeros.

En todo caso, no hay duda de que la parmesana se movía como pez en el agua en las altas esferas. Desde que el embajador William Edem llegó a España, advirtió -acabamos de ver un ejemplo- las exquisitas y halagadoras maneras de la reina, algo que no le niega prácticamente nadie y que es normal encontrar en las cartas de los embajadores de toda Europa. Muchos pensaron que utilizaba esas «técnicas femeninas» para manipular a su marido y a los que lo rodean, pero ahora -sin entrar en polémicas- queremos resaltar la habilidad -para bien o para mal- de aquella consorte, que fue una de sus mayores armas políticas para ejercer y ampliar su poder. Pronto veremos cómo esta idea -la de la intriga personal y constante- es insuficiente para explicar la naturaleza de la influencia de aquella mujer. No olvidemos que Carlos y María Luisa, por muy cordiales que fueran cuando se mostraban en la Corte, fueron bastante remisos a ser esclavos del ceremonial y que se prodigaban bastante poco en la concesión de audiencias. Existían otros caminos para hacer política.

La segunda de las dos explicaciones alternativas a los juegos secretos de la pareja real con Londres y París, se refiere a un inusitado concepto que aporta la correspondencia estudiada y del que nos ocuparemos en breve: la existencia de un «partido de la

30. La Vauyugon à Montmorin. Madrid, le 14 Décembre 1788. A.A.E., Correspondance politique. Espagne, 625, pp. 426-427.

31. La Vauyugon à Montmorin. Madrid, le 31 Décembre 1788. A.A.E., Correspondance politique. Espagne, 625 .

32. Edem to Leeds. Madrid, December $12^{\text {th }} 1789$. N.A., F.O., $72 / 15$. 
reina» en la Corte; algo más que una camarilla conspiradora, un grupo con un proyecto político definido.

\section{EL «PARTIDO DE LA REINA»Y LA DESMEMBRACIÓN DE LA CLIENTELA DE FLORIDABLANCA}

¿Cuál fue el motivo real de la caída de Floridablanca? La historiografía tradicional ha cargado las tintas en la influencia de María Luisa de Parma, supuestamente ansiosa por el ascenso de su favorito, Manuel Godoy. Autores más reflexivos, como Carlos $\operatorname{Seco}^{33}$ y Emilio La Parra ${ }^{34}$ han señalado el peso de las urgencias de la política con Francia (erróneamente planteada por el timorato ministro) y la oposición del partido aragonés, como alternativas a la manida conspiración mujeril. La correspondencia que ahora analizamos nos aporta un punto de vista que combina varios motivos y que hace algo más razonable el papel de la reina en aquel cambio político.

Los observadores percibían la pérdida de influencia de Floridablanca. Uno de los momentos clave fue su relevo de la secretaría de Gracia y Justicia, lo que suponía «una considerable disminución de su peso y trascendencia tanto en la Corte como en el resto del país». Compatibilizando su puesto como secretario de Estado (1777) y secretario interino de Gracia y Justicia (1782), Floridablanca había conseguido afianzarse en el poder y crearse una gran clientela política. La creación de la Junta de Estado había sido un paso más hacia el denominado «despotismo ministerial». Observamos ya en abril de 1790 que «otros han ganado influencia sobre Sus Católicas Majestades» por lo que «hay motivos para sospechar (...) que en breve veremos a Su Excelencia completamente retirado de la dirección de los asuntos públicos». La mayor aportación de esta carta de Anthony Merry al Foreign Office es la observación sobre la pérdida por parte de Moñino de la capacidad para alimentar su red clientelar:

«...el patronazgo que ha perdido al ser privado de la disposición de las preferencias en los cargos civiles y eclesiásticos, supone una considerable disminución de su peso tanto en la Corte como en el Estado» ${ }^{35}$.

No está de más que recordemos las enormes atribuciones que tenía el secretario de Gracia y Justicia:

««...todo lo perteneciente al gobierno de tribunales, con la nominación de personas para presidentes, gobernadores y ministros de ellos, y los de las chancillerías y audiencias; el nombramiento de inquisidor general y ministros del Supremo de la Inquisición»; la provisión de todos los corregimientos que no estuvieran destinados a Hacienda y Guerra; todo lo que incumbe al Real Patronato, incluyendo el nombramiento en la Península de arzobispos, obispos y demás dignidades eclesiásticas; lo concerniente a las Casas Reales; el

33. Seco Serrano, Carlos: Godoy, el hombre y el politico, Madrid, 1978

34. LA PARRA LóPEz, Emilio: Manuel Godoy, la aventura del poder, Barcelona, 2002

35. Merry to Leeds. Aranjuez, April 29 $9^{\text {th }} 1790$. N.A., F.O., 72/16, pp. 293-296. 
despacho de los títulos de Castilla y demás mercedes y el de «sisas municipales, arbitrios, rompimiento de tierras de pastos y las concesiones de facultades a los pueblos $»)^{36}$.

El nuevo secretario, Antonio Porlier había tenido una larga carrera bajo el reinado de Carlos III pero conseguiría sus mayores logros en los primeros años gobierno de Carlos IV ${ }^{37}$. Vinculado al que podemos llamar, «partido dominante», participó en el posterior proceso al conde de Aranda. El sustituto de Porlier en Gracia y Justicia, Pedro Acuña, estaría aún más vinculado a Godoy; pero sigamos por ahora con Floridablanca.

Si hacemos caso a Fitzherbert, futuro lord St. Helens y el más influyente de los embajadores ingleses en el periodo analizado, las concesiones a la amenazante Inglaterra durante el «affaire Nootka» limaron considerablemente la popularidad del conde. Exageradas listas de pretensiones inglesas circularon para predisponer al público a favor de la ruptura bélica ${ }^{38}$, dando lugar a una lucha entre Floridablanca y un surtido grupo cortesano que quería convencer a Carlos IV de la conveniencia de la guerra. Entre ellos, podemos reconocer a Bernardo de Iriarte y al duque de Almodóvar (muy cercanos a Godoy) ${ }^{39}$. El miembro más influyente de esa corriente de opinión anti-inglesa era la reina, de quien se decía que empezaba a discutir al conde murciano en los «asuntos domésticos» (el tema del patronazgo político-administrativo estaba, a buen seguro, sobre la mesa).

El 2 de agosto de 1790, Godoy aparecía por primera vez en la correspondencia británica como el «favorito de la reina» y parte activa en los asuntos de Corte ${ }^{40}$. En octubre, podemos leer que existía un «nacional odium» hacia Floridablanca, lo que no había de ser muy tenido en cuenta dado «el intrascendente peso que la voz pública tiene en este país cuando se opone a la autoridad de la Corona $»^{41}$. El número de enemigos de Floridablanca crecía alimentado por la envidia que despertaba su poder y por las excusas proporcionadas por los reveses políticos. Además del fracaso diplomático y la humillante capitulación provocadas por el asunto de Nootka, el conde tenía que responder por el abandono de Orán y sobre todo por su oscilante política respecto a Francia. La corte española había aceptado la presencia del embajador revolucionario y

36. Castellano, Juan Luis: Gobierno y poder en la España del siglo XVIII, Granada, 2006, p. 160. E1 profesor Castellano cita una serie de decretos de 1754 en los que se mencionan las competencias de cada secretaría (AHN, Consejos, lib. 1481, ff. 133-138 y Biblioteca Nacional, Ms. 11266, números 95-96).

37. En 1789 había sido nombrado miembro del Consejo de Estado, donde se mantendría hasta el final del reinado. Aunque ocupó la secretaría sólo un par de años, tuvo la suerte de unificar bajo su mando la Gracia y Justicia de Indias (que ya ocupaba desde 1787) y la de España. Quizá por su prestigio y su avanzada edad (68 años), igual que ocurriría en 1792 con la interinidad de Aranda en Estado, Porlier estaba llamado desde el principio a ocupar el cargo de manera transitoria. En 1791 fue nombrado marqués de Bajamar y en 1792 llegó a presidente y gobernador del Consejo de Indias e ingresó en la Orden de Carlos III (Fichoz, n ${ }^{\circ}$ 002534). Para más datos sobre el personaje, ver: GUIMERÁ PERAZA, M.: «Don Antonio Porlier, marqués de Bajamar (1722-1813)», Anuario de Estudios Atlánticos, 27, 1981, pp. 113-208.

38. Fitzherbert to Leeds. Madrid, July $5^{\text {th }} 1790$. N.A., F.O., 72/18, pp. 11-12.

39. Fitzherbert to Leeds. San Ildefonso, October $24^{\text {th }} 1790$. N.A., F.O., $72 / 19$, pp. 186-189.

40. Fitzherbert to Leeds. Madrid, August $2^{\text {nd }} 1790$. N.A., F.O., 72/18, pp. 143-145.

41. Fitzherbert to Leeds. Escorial, October $28^{\text {th }} 1790$. N.A., F.O., 72/19. 
del contrarrevolucionario, intentando apoyar disimuladamente a ambos bloques, pero sin tener contento a ninguno, pues no admitía ni rechazaba el juramento de Luis XVI a la Constitución de 1791. De puño y letra del propio Moñino sabemos que ésa era precisamente su estrategia ${ }^{42}$.

El 28 de febrero, St. Helens informó a su Corte del «inesperado» cese de Floridablanca como secretario de Estado y de la supresión de la Junta por él creada. Aunque no se conociese la causa inmediata de este cambio, estaba motivado «indudablemente (...) por la reina y su partido». Su sustituto interino, el conde de Aranda, no pertenecía a este «partido imperante» pero:

«Presumo que ha sido considerado necesario situar a la cabeza de los asuntos de Estado a una persona de los mayores rango y carácter para reconciliar al público con el cese del conde de Floridablanca, cuyas maneras conciliadoras le habían asegurado un importante número de partidarios, especialmente entre las clases más bajas. Se esperan muchos otros cambios muy pronto»..$^{43}$

Poco después salieron a la luz nuevos rumores que justificaban la caída, como unos disturbios en Madrid; pero el grupo afín a María Luisa de Parma seguía siendo considerado como el detonante. Lord St. Helens demostró ser un observador comedido, intentando estudiar durante los siguientes meses los movimientos y miembros del partido. En los reportes de la embajada británica en Madrid, María Luisa de Parma y «el Favorito» no eran protagonistas de una absurda sucesión de chismes de alcoba, sino personajes influyentes en el juego de poderes de la Corte.

El cambio en el gobierno no beneficiaba a las perspectivas de alianza hispanobritánica. St. Helens se sentía decepcionado por la «frialdad y la desgana» del conde de Aranda, claramente francófilo, en relación a las negociaciones iniciadas por su antecesor, sin «dejar caer la más mínima expresión que indique su deseo personal» de que aquellas prosperen ${ }^{44}$. A pesar de todo, en el Foreign Office no se lamentaban del ascenso de Aranda, pues al menos «decidirá la adopción de un plan político fijo, en lugar del confuso y contradictorio sistema que siguió el conde de Floridablanca, embarcándose a la vez en demasiadas negociaciones distintas, todas ellas sobre términos inconsistentes»»..$^{45}$

Floridablanca habría aceptado «este giro de la fortuna» $\sin$ dramatizar ${ }^{46}$, pero pronto se quebraría este retiro pacífico. Acusado de malversación de fondos sería per-

42. «Los medios y evasiones que se buscaron y el último plan preliminar para el tratado desalentaron a la Corte de Londres y fue cayendo en el olvido este negociado»; y «El sistema adoptado y seguido hasta ahora con la Inglaterra ha sido el de mantener con ella la posible buena armonía, sin fiarse de sus palabras y conducta, a pesar de las protestas y deseos de nuestra mayor unión y amistad que nos ha hecho frecuentemente» (FloridablancA, Conde de: El Testamento Político del Conde de Floridablanca-ed. de Antonio Rumeu de Armas-, Madrid, 1962).

43. St. Helens to Grenville Madrid, February 28 ${ }^{\text {th }} 1792$. N.A., F.O., 72/23, p. 95.

44. St. Helens to Grenville. Madrid, $8^{\text {th }}$ March 1792. N.A., F.O., 72/23, pp. 119-121.

45. Grenville to St. Helens Whitehall, April $20^{\text {th }} 1792$. N.A., F.O., 72/23, pp. 214-216.

46. St. Helens to Grenville. Madrid, March $12^{\text {th }} 1792$. N.A., F.O., 72/23, p. 124. 
seguido por sus enemigos. Estos, según F.J. Jackson, querían contrarrestar los escrúpulos de Carlos IV por haber roto «la promesa que le había hecho al anterior rey en su lecho de muerte de nunca romper con un sirviente tan fiable y abnegado». El «partido predominante» estaba detrás de la conspiración ${ }^{47}$.

Respecto a Aranda (sobre el que profundizaré en el próximo apartado), su puesto era interino, los propios contemporáneos daban por hecho que se estaba buscando un secretario definitivo. El embajador St. Helens decía que «no parece haber motivo para su deseo [de Aranda] de hacerse cargo de una oficina cuyos asuntos son extremadamente fatigosos para una persona de sus años y creciente debilidad». Para sustituirle sonaba el conde de Fernán Núñez, tantos años embajador en París y muy cercano a la reina ${ }^{48}$. En marzo de 1792, Godoy no estaba en los pronósticos.

Es interesante el párrafo que el diplomático inglés dedicó a hablar del pacto alcanzado entre Aranda y el partido de la reina («Queen's party» ${ }^{49}$ ), con el que se disputaba a los hombres de gobierno:

«En general [Aranda] no tiene tiempo para prestar mucha atención a los negocios de su departamento, ya que los términos de su arreglo con el partido de la reina no están completamente estipulados aún, por lo que una gran agitación prevalece en el interior de Palacio. La principal lucha se librará sin duda por la dirección del departamento de finanzas, pero se dice que el Señor Gardoqui mantendrá el puesto, ya que se dice que hizo hace algún tiempo las paces con el favorito, y que -a pesar de sus obligaciones hacia el conde de Floridablanca- estuvo profundamente implicado en las intrigas que ocasionaron su dimisión. El nuevo gobernador del Consejo de Castilla está totalmente de parte del partido imperante $»^{50}$.

Gardoqui supo seguir la dirección del viento que soplaba en la Corte y se mantuvo en el gobierno de Godoy hasta 1796. La última frase hace referencia al conde de la Cañada, hombre de peso en los primeros años del reinado de Carlos IV (promotor de los procesos contra Floridablanca y Aranda). Ambos fueron parte importante del llamado «partido de la reina».

En marzo se conoció también el cese de Francisco Moñino (hermano de Floridablanca) como presidente del consejo de Indias, su sustituto fue el mencionado Antonio Porlier. Ya era evidente que todos los partidarios de Floridablanca estaban siendo alejados del poder «por la reina y su partido, y sin ninguna oposición por parte del conde de Aranda ${ }^{51}$. Los siguientes reportes al Foreign Office nos van informando de los movimientos de la Corte española: María Luisa se suponía tan inmiscuida en la criba, que los asuntos internos se habrían suspendido unos días hasta su restableci-

47. Jackson to Grenville. Madrid $2^{\text {th }}$ July 1792 . N.A., F.O., 72/24, pp. 88-93.

48. St. Helens to Grenville. Madrid, $1^{\text {st }}$ March 1792. N.A., F.O., 72/23, pp. 107-108.

49. Léase «grupo», «camarilla», o como quiera llamarse a un sector de la corte con una personalidad política propia.

50. St. Helens to Grenville. Madrid, $8^{\text {th }}$ March 1792. N.A., F.O., 72/23, pp. 119-121.

51. St. Helens to Grenville. Madrid, $24^{\text {th }}$ March 1792. N.A., F.O., 72/23, pp. 148-149. 
miento de un pequeño reposo ${ }^{52}$; el nombramiento de Godoy como duque de Alcudia hacía pensar que sería Grande de España de primera clase en breve; crecía el descontento en la Corte, tanto con Aranda como con el Favorito, cuyo ascenso tampoco era bien visto por St.Helens:

«Obviamente, esta muestra de profusión sobre tan odiosa persona, ha dado lugar a descontento, y el Señor Aranda es el más culpado por haberlo permitido, ya que se supone que hay motivos para pensar que la firme oposición de Floridablanca a este gran ascenso es lo que ocasionó su cese. La verdad parece ser que Aranda se opuso a él, y parece-según se ha filtrado- que no existe ninguna unión real o cordial entre el Favorito y él. Un fuerte cambio tendrá lugar aquí, y mientras este sistema prevalezca, no parece improbable que esta Corte sea ahora no menos famosa por la rápida sucesión de sus ministros como lo fue por su permanencia $\rangle^{53}$.

En las promociones de mayo de 1792 encontramos el ascenso de José Godoy (padre de Manuel) al puesto de gobernador del Consejo de Hacienda. Aranda dirigía la política exterior (el embajador republicano había sido aceptado ${ }^{54}$ ), pero era un convidado de piedra en los asuntos internos pues «pierde crédito diariamente con la reina y su favorito quienes usurpan todo el patronazgo de la Corte y disponen de él sin la participación de los ministros» ${ }^{55}$. Una vez más, el patronazgo es la clave del poder.

Los hechos se sucedían en la segunda mitad de 1792. El nombramiento de Pedro Acuña como secretario de Gracia y Justicia, junto al ascenso de Cañada a la presidencia del Consejo de Castilla, aparecieron en la correspondencia británica como «la mayor prueba que puedo dar a Su Señoría de la irresistible prevalencia de la influencia de la reina». Aranda no controlaba ni Gracia y Justicia ni la Cámara de Castilla, así que no es de extrañar que Jackson observase que el conde no participaba «en la distribución de los favores cortesanos» y considerase probable que el «partido preeminente» quisiera deshacerse de «un socio tan pasivo» ${ }^{56}$. Tan inesperado era que el joven Godoy sustituyese al aragonés, que el candidato mejor situado parecía el conde de la Cañada.

Cuando Godoy accedió al Consejo de Estado (con la indignación de los consejeros), Jackson vio en tamaño ascenso otra prueba de que «la reina tiene ahora en sus manos el casi descontrolado gobierno de este país». El destierro de Floridablanca se consideraba una venganza de María Luisa y los ascensos como la antesala del cese de Aranda:

«Esta medida y las reprobables promociones que recientemente se han hecho en plazas de confianza e influencia, han ocasionado una gran fermentación en el público, donde el clamor contra la reina y su partido es muy fuerte» ${ }^{57}$.

52. St. Helens to Grenville. Madrid, $2^{\text {nd }}$ April 1792. N.A., F.O., 72/23, pp. 170-171.

53. St. Helens to Grenville. Madrid, $19^{\text {th }}$ April 1792. N.A., F.O., 72/23, pp. 201-203.

54. Conocemos el desagrado de $\mathrm{M}^{\mathrm{a}}$ Luisa hacia el nuevo embajador por su correspondencia con Godoy.

55. St. Helens to Grenville. Madrid, $25^{\text {th }}$ June 1792. N.A., F.O., 72/23, pp. 82-86.

56. Jackson to Grenville. Madrid, $12^{\text {th }}$ July 1792. N.A., F.O., 72/24, pp. 112-115.

57. Jackson to Grenville. Madrid, $19^{\text {th }}$ July 1792. N.A., F.O., 72/24, pp. 124-127. 
En septiembre de 1792, Jackson se hacía eco de un rumor del que decía tener pruebas. Según él «en sus planes por asegurar su influencia en el gobierno, parece que la reina de España ha prestado no menos atención al futuro que al presente» y pretende convencer al monarca para que prolongue la mayoría de edad del heredero hasta los veinticinco años con ella como regente en caso de que él muriese. Se comentaba que el conde de la Cañada había hecho esta propuesta al Consejo de Castilla, obteniendo un rechazo unánime ${ }^{58}$. Ciertamente se podría escribir un libro sólo con los rumores -fundados o no- que corrieron sobre María Luisa de Parma en los años en que fue reina.

Era de esperar que, al caer Aranda, el cese (inesperado tanto para él como para el público) fuese atribuido por Jackson «a un antiguo proyecto para poner al favorito a la cabeza de los negocios que a ningún otro hecho presente» ${ }^{59}$. El embajador apuntaba la importancia de Eugenio Llaguno, nombrado secretario de Godoy y consejero de Estado. Llaguno era un cualificado asesor para el inexperto Godoy, había sido oficial de la secretaría de Estado durante años, además de secretario de la Junta de Estado.

La última carta diplomática que voy a citar en este artículo la fechó el embajador Jackson el 4 de diciembre de 1792. En ella reconocía el peso del factor internacional y de la presión de la Iglesia (el Nuncio papal y el Inquisidor General) en la caída de Aranda, lo que no significaba que la reina no estuviese muy presente (se dice que el noble aragonés se oponía tajantemente al nombramiento de Godoy como comandante del ejército). Dos de los tres supervivientes del gabinete de Floridablanca-Campo Alange y Gardoqui- tenían los días contados en el gobierno, y el tercero -Valdéshabía sabido ganarse a Godoy. Se cree además que el ascenso de este no había acabado aún: «La opinión general es que será nombrado primer ministro en breve y que tratará con el rey todos los negocios del Estado mientras que el resto de ministros sólo podrán informarle a él ${ }^{60}$.

Manuel Godoy era retratado como el guardia de Corps colmado de honores con tan sólo veinticinco años que fue. Es necesario fijarse en dos figuras destacadas por Jackson ya que, para él, Godoy era una persona al que no se le conocía talento alguno y que «siempre rechazó entrar a discutir ningún tema sobre el que no hubiera podido prepararse previamente ${ }^{61}$. La primera figura es su amigo Pedro Acuña, y la segunda, Eugenio Llaguno, que gozaba del respeto del público y con el que se intentaba cubrir el poco respeto que inspiraba el nuevo secretario de Estado.

Aranda, por su parte, permanecía en el Consejo de Estado con el aprecio del rey, pero «estoy seguro de que se le ha insinuado que su presencia en la Corte sería dispensada de buena gana ${ }^{62}$. Nada se dice sobre la cama de María Luisa, todo se plantea a nivel político, quizá con el desprecio que el absolutismo podía causar a un inglés de la

58. Jackson to Grenville. Madrid, $10^{\text {th }}$ September 1792. N.A., F.O., 72/24, pp. 229-231.

59. Jackson to Grenville. Escorial, $16^{\text {th }}$ November 1792. N.A., F.O., 72/25, pp. 103-104.

60. Jackson to Grenville. Madrid, $4^{\text {th }}$ December 1792. N.A., F.O., 72/25, pp. 196-200.

61. Ibidem.

62. Ibid.

REVISTA DE HISTORIA MODERNA Nº 28 (2010) (pp. 121-146) ISSN: 0212-5862 
época, pero nada más. Tanto Merry, como Edem, Fitzherbert o Jackson, hicieron una radiografía muy solvente de los movimientos políticos de la Corte española, acertando en gran medida con sus predicciones.

El primer gobierno de Godoy duró trece meses. Sus miembros -en palabras de La Parra ${ }^{63}$ - eran «heredados de Aranda y en su mayoría nombrados en la época de Floridablanca». Campo Alange y Valdés se mantuvieron respectivamente en la secretaría de Guerra y en la de Marina hasta noviembre de 1794, Gardoqui en la de Hacienda hasta 1796; los tres eran hombres de Floridablanca que supieron sobrevivir a la primera oleada. En 1794, Llaguno sustituyó a Acuña en Gracia y Justicia, evidente cargo de confianza al servicio del clientelismo de Godoy, el amigo íntimo de los reyes. En sólo dos años, el valido había cambiado a todos los oficiales de la secretaría de Estado.

Tras 23 años a la sombra de Carlos III, Carlos IV había acabado en poco tiempo (quizá en demasiado poco, incluso para un rey absoluto) con el gabinete político y administrativo de su padre. El medio para hacerlo no había sido otro que el «partido de la reina», que había llenado la Corte de estómagos agradecidos, pero también de enemigos que no dejarían de crecer en el vaivén de ceses y nombramientos de aquel reinado, en la búsqueda desesperada por tocar la tecla política adecuada en momentos tan difíciles.

No hay que olvidar que con los cargos cortesanos estaba ocurriendo lo mismo que con los político-administrativos. Carlos y $\mathrm{M}^{\mathrm{a}}$ Luisa nombraron para aquellos puestos a las mismas personas que los habían servido como príncipes de Asturias; esto es, a su gente de confianza ${ }^{64}$. Tampoco colaboraron con el prestigio de Carlos y $\mathrm{M}^{\mathrm{a}}$ Luisa su creciente desatención a las costumbres heredadas del ceremonial cortesano, ni su progresivo distanciamiento de la Corte, reduciendo al mínimo las apariciones públicas. Precisamente, en las reuniones privadas de la camarilla de los príncipes de Asturias y en las habitaciones de la reina, se forjó el ascenso del conde de Aranda, como prueba el epígrafe siguiente.

\section{ARANDA Y LA REINA M ${ }^{\mathrm{a}}$ LUISA}

Tradicionalmente se ha mantenido la imagen de Aranda como un hombre ajeno a las intrigas cortesanas y sobre todo al entorno de la reina $\mathrm{M}^{\mathrm{a}}$ Luisa. Esta idea puede verse matizada por cierta documentación que relaciona directamente al conde con la parmesana en los años previos a su nombramiento como secretario interino de Estado.

En los textos recogidos por Muriel y Ferrer Benimeli, Aranda mostraba su sorpresa por la llamada de la reina y de su hombre de confianza. Debido al enfriamiento de sus relaciones con la pareja real, es plausible el asombro del conde, pero es preciso aclarar que el desencuentro procedía de 1789 y no de 1781 . Veamos parte del texto:

63. LA PARRA, op. cit., pp. 152-154.

64. Ver: Gómez Centurión, Carlos: «Al cuidado del cuerpo del Rey: los sumilleres de corps en el siglo XVIII», en Gómez Centurión, Carlos (coord.): Monarquía y Corte en la España Moderna. Anejo II de Cuadernos de Historia Moderna, Madrid, Universidad Complutense, 2003, pp. 199-239. 
«Desde que me restituí de la Embajada de Francia (...) en el año de 1787, y muriendo el augusto rey padre en 1788, entró V.M. a sucederle, es bien notoria mi vida retirada hasta la separación del conde de Floridablanca al fin de febrero de $1792 »^{65}$.

Estas palabras pueden hacer pensar que desde el Plan de gobierno de 1781, y hasta 1792, Aranda se había mantenido alejado de Carlos y Mª Luisa. Pues bien, hay pruebas más que suficientes para asegurar que Aranda le estuvo haciendo la Corte a M Luisa de Parma desde su regreso de la embajada de París, en 1787. Gracias a unos - prácticamente inéditos ${ }^{66}$ - Papeles para S.M. la Reina ${ }^{67}$ conocemos unas quejas de Aranda a $\mathrm{M}^{\mathrm{a}}$ Luisa a los pocos días de haber accedido al trono.

Se trata de cinco cartas. En la primera (la que voy a utilizar aquí, fundamentalmente), el conde recordaba el favor que le habían venido dispensando los príncipes de Asturias, con el que había alcanzado «el colmo» de su «felicidad». Es lo que le quedaba por esperar «después de haber servido a mis Reyes y Señores, y a mi patria en diversas carreras, y en todas con desempeño de mi honor y de mi obligación». A nada más alto podía esperar un hombre honrado que al «buen concepto público». Así veía Aranda la situación hasta la muerte de Carlos III:

«Gozaba yo de antiguo la honra de hacer mi corte a V.M. algunas veces en su interior tertulia al tiempo de la partida de juego del Rey; y la de ser tratado como los demás concurrentes a ella con igual afable benignidad de V.M. En este estado falleció el Rey augusto Padre a cuyas cenizas tributé mi último respeto, acompañándolas al Escorial (...) y en el intermedio de este servicio se dignaron Vuestras Majestades de explicar con la mayor bondad que sin alteración continuasen a la misma hora y ocasión los acostumbrados a tanto favor (...) Aspirando al mayor respeto, expuse al Rey en la hora de su café, si me animaría a dar crédito a la explicación que tenía entendida, respondiéndome S.M. con agrado y su natural franqueza, que habiendo disfrutado hasta entonces aquella concurrencia, sin duda debía continuarla. Hasta V.M. misma, algo distante, preguntando al Rey de que se hablaba, y respondiendo S.M. con lo dicho, se dignó ratificarlo desde su asiento» ${ }^{68}$.

Pero algo había cambiado en la actitud de la ahora reina. Y aquella misma noche, Aranda experimentó la amargura de su desprecio:

«Noche fatal para mi respeto, y amor a Vuestras Majestades, aquella del mismo día sábado 20 de Diciembre en que presentándome como las anteriores, empecé a percibirme de un silencio exclusivo de V.M.». ${ }^{69}$.

Tras dos o tres noches sufriendo ese desdén, Aranda pidió a un familiar que intercediese y le preguntase a $\mathrm{M}^{\mathrm{a}}$ Luisa por los motivos de esa actitud. La reina le había hecho llegar que «no mediaba causa» para su recelo, pero:

65. MuRIEL, Andrés: Historia de Carlos IV, en BAE, Madrid, Atlas, 1959, t.1, p. 95.

66. La única alusión a la fuente que he encontrado es de R. Olaechea y J.A. Ferrer Benimeli. La citan como inédita en la $2^{\text {a }}$ edición de El conde de Aranda: mito y realidad de un político aragonés (1998), pero no utilizan el texto ni indican la referencia de archivo.

67. AHN, Estado, leg.2863-1, exp.7.

68. Aranda a Ma Luisa. Madrid, 24 de enero de 1789 (Ibidem, doc.4).

69. Ibid. 
«Señora, esta explicación tan agradable no alcanzaría a mi Serenidad, prosiguiendo V.M. también en manifestarme su desvío en los actos públicos de su corte al tiempo de la mesa y al de su café (...) que (...) no cabe atribuirle a casualidad (...) pues entre tantos que me han rodeado, he venido a ser siempre como el escogido para la sensible distinción de olvidado» ${ }^{70}$.

Aranda achacaba esa desgracia a posibles comentarios con que la malevolencia podía haber engañado a la reina. Recordando sus años de servicio y su sangre derramada por la Monarquía, rogaba a $\mathrm{M}^{\mathrm{a}}$ Luisa que le comunicase los motivos de su distanciamiento. En los meses siguientes, su ansiedad se fue incrementando. En cartas del 14 de marzo y 18 de agosto de 1789 , y de 3 de febrero y 30 de abril de $1790^{71}$, siguió pidiendo audiencia.

El familiar al que Aranda se refiere es el conde de Montijo, quien no consiguió que la situación de su sobrino político mejorase. La reina le contestaba con argumentos vagos como que los reyes están a veces de buen humor y otras de malo (¿ocho meses de mal humor?, se preguntaba Aranda). Otras veces respondía con un lacónico «está bien». Montijo empezó a experimentar la sequedad de la reina cuando se acercaba a entregar las cartas, que consideraba contraproducentes.

En carta a Montijo, Aranda explicaba los motivos de su insistencia. Las malas experiencias previas pesaban y quería demostrar que hacía lo imposible por la gracia regia y que no merecía lo contrario. Al final, a Aranda no le quedó otra posibilidad que resignarse, como le confesaba a su amigo y familiar:

«Me recuerdas mi opinión, diferente a la tuya, como que yo he creído siempre que no debía omitir tales diligencias; y tú que sería mejor orillarlas. Esto hubiera sido cuestionable si yo no hubiera tenido que ausentarme, pero en el caso del día he pensado (y no me arrepiento) que debía dar el último paso para que no se creyese arriba que yo pudiese haberme enfriado en buscar mi descargo hasta la final posibilidad (...) Yo he practicado cuanto me cabía y queda al tiempo lo demás. Pasaré a este sitio, besaré las manos que debo y me conformaré con la superior voluntad de mi mayor respeto» ${ }^{72}$.

$\mathrm{M}^{\mathrm{a}}$ Luisa era la mediadora de la gracia regia. Aranda nunca habría asediado el monarca con cartas (sólo mandó una carta conjunta), algo que intentó con la reina. Poco más tarde, el conde volvió a ser llamado por la consorte. Volvamos al relato de su acceso a la secretaría de Estado en 1792, contenido en un manuscrito justificativo:

«Cuatro o seis días antes de esta providencia me sorprendió una carta de don Manuel Godoy, a quien yo no tenía tratado, por mano de don Pedro de Acuña, que personalmente vino a entregármela al entrar de una noche y exigió de mí que le diese respuesta. Su contenido se reduce a ser voluntad de Su Majestad que me trasladase al sitio de Aranjuez en aire natural de hacer mi Corte y que solicitase una audiencia a la reina, mi señora, que se me concedería, y allí sabría ambas reales voluntades. Contestéle desde luego con mi obediencia, y retiróse Acuña con mi respuesta.

70. $I b$.

71. Ib., docs. $5,6,8$ y 10 .

72. Aranda a Montijo. Madrid, 2 de mayo de 1790. Ib., doc.18. 
Cumplí al tercero día, y por el medio regular de la camarera hice llegar mi solicitud a la Reina, quien benignamente me la acordó para después de la comida de V.M. Indicáronme VV.MM. su ánimo; mas siendo ya tarde, me dijeron que volviese en la mañana siguiente por el mismo lado. Así lo practiqué, y en presencia del duque de la Alcudia se explicaron VV.MM. abiertamente conmigo» ${ }^{73}$.

En el Diario del conde (localizado por Ferrer Benimeli) podemos leer sobre su relación con los reyes durante los ocho meses que dirigió la secretaría de Estado. Que el equivalente de la época a un primer ministro tuviera que contactar con una camarera mayor ${ }^{74}$ para conseguir su nombramiento, o que tuviera que acceder al rey a través de las habitaciones de la reina ${ }^{75}$ no es corrupción, ni ginecocracia, sino -ni más ni menosla Corte del Antiguo Régimen.

Como es lógico, este papel de mediadora, unido a la confianza de su marido, le daban a $\mathrm{M}^{\mathrm{a}}$ Luisa un gran poder. De ahí la obsesión por no importunar a la reina que Aranda reflejó en su Diario $^{76}$. En el manuscrito, los comentarios sobre la actitud del rey son siempre positivos y amables (v.g. «estuvo muy festivo y amable»), eran la reina y su amigo Alcudia los que daban la cara. Cuando fue relevado del puesto, Aranda se quedó con la sensación de que era $\mathrm{M}^{\mathrm{a}}$ Luisa quien lo cesaba, ya que fue ella quien le dio la noticia; el rey se mantuvo al lado del aristócrata durante la escena:

«El Jueves 15 de noviembre, habiendo llegado las noticias de Francia (...) Entré y empezaron Sus Majestades por hablar de ellas. Luego dijo la Reina: «Aranda estarás muy cansado con la vida que haces (...) te queremos conservar para las cosas mayores, y aliviarte de las molestas» (...) y el Rey desde el principio de esta conversación se había mantenido a mi lado apoyado, y como recostado sobre mi hombro derecho, muy expresivo» ${ }^{77}$.

Fuera de las paredes de Palacio, también se percibía la influencia de la reina, es cierto. Desde el principio, esa fue un arma contra Godoy o contra el rey. La oposición interpretó desde muy pronto que Aranda era un mero testaferro de $\mathrm{M}^{\mathrm{a}}$ Luisa. Son palabras dirigidas en 1792 al conde de parte de «El amigo del Rey y de VMD», quien le informaba de «cómo piensa el Reino»:

«Los sucesos desde que VMD manda, tan contrarios a todo el Reino, y aún al nombre de VMD y su lustre, son pruebas de que han buscado a VMD por tapadera para autorizar maldades; VMD ha puesto un borrón a su buen nombre y persona que jamás se borrará, y de un héroe ha venido a pasar por hombre sin espíritu, sin honor, y que el deseo de mandar le ha hecho degenerar de su grandeza. Los grandes lo dicen bien, el Reino, la Europa toda

73. Ferrer Benimeli, José A.: «El conde de Aranda, primer secretario de Estado», en Suma de Estudios en Homenaje al doctor Canellas, Zaragoza, Facultad de Filosofía y Letras, 1969, pp. 355-378.

74. Ver: LÓPEZ-CORDón CORTEZO, Ma Victoria: «Entre damas anda el juego: las camareras mayores de Palacio en la Edad Moderna», en GómEZ CENTURIÓN (coord.), op. cit., pp. 123-152.

75. «Desde el principio tuve el cuidado respetuoso de presentarme a la Reina en su cuarto los días de despacho al volver S.M. del paseo (...) En la correspondencia de Francia (...) iba para el regreso del Rey, y me hacían entrar luego dando el santo al cuarto de la Reina, siguiendo siempre Alcudia» (Ibidem, p. 365).

76. «En los tres despachos por semana jamás he tocado especie que pudiese disgustar a la Reina, ni a nadie» (FERRER BENIMELI, op. cit., p. 365).

77. Ibidem, p. 368. 
está admirada de que un conde de Aranda sea ministro solo en el nombre y que se valgan de él para sostener el escándalo y la maldad ¿quién creyera que el gran conde de Aranda había de hacer un papel tan bajo? ¿Quién pudiera esperar de un conde de Aranda había de tener tan poco espíritu? ¿Quién podía persuadirse que había de autorizar la maldad? Nadie, más ello es así. Floridablanca cayó, como lo dice el Reino, lo pregonan las gacetas extranjeras y lo corroboran los hechos, porque no accedió a lo que no era justo, a lo que no convenía al Rey, a lo que era indecoroso y poco decente a ambas majestades y perjudicial al reino, pero VMD lo autoriza. Triste situación, ¿cómo en otro tiempo quería VMD ser un testaferro y que sólo se valgan de VM para sostener el capricho y la coquetería?, ¿cómo puede VMD sufrir tanto escándalo?, ¿cómo tantos gastos excesivos?, ¿cómo tantas donaciones y gracias sin medida y sin tasa?, ¿cómo el deshonor mismo del rey?» ${ }^{78}$.

Pero hay que conocer la Corte del Antiguo Régimen y el ascendente papel político de las consortes europeas en el XVIII, en lugar de escuchar sólo las voces de los anónimos de la época o las resentidas e interesadas fuentes fernandinas y liberales posteriores a 1808. Carlos no era un cero a la izquierda, de ahí a la realidad media un abismo. Si hacemos caso a Godoy, fue precisamente un desencuentro entre el rey y Aranda en una sesión del Consejo la que supuso la desgracia del conde, que hasta el momento sólo había sido relevado de la secretaría de Estado, cargo que él mismo había pedido desempeñar como interino. En el relato de esa famosa sesión, Godoy retrató a Carlos IV con la autoridad que se le suponía a un monarca absoluto, ni más ni menos («Carlos IV escuchó aquel dictamen sin dar muestra de alterarse. Todo el brillo de la majestad resplandecía en sus ojos con una luz serena; veíase al Rey más que al hombre en su noble y templada compostura»). Tras el atrevido alegato de Aranda, las siguientes palabras del rey habrían precipitado su caída: «Con mi padre fuiste terco y atrevido, pero no llegaste a hasta a insultarle en su Consejo» ${ }^{79}$. ¿Por qué creer ciegamente unas fuentes y obviar por completo otras?

\section{UN EPISODIO DE «MATRONAZGO»Y PODER DE MARÍA LUISA}

Probablemente no sea el caso de Godoy el que pueda indicarnos la influencia política de $\mathrm{M}^{\mathrm{a}}$ Luisa de Parma. El extremeño era amigo ${ }^{80}$ y confidente tanto del rey como de la reina. Hay otros episodios más significativos de la iniciativa política de $\mathrm{M}^{\mathrm{a}}$ Luisa $\mathrm{y}$ de su influencia en los nombramientos.

El 14 de diciembre de 1796, el recién nombrado secretario de Hacienda, Pedro Varela fue duramente reprendido por el Príncipe de la Paz. En una lista de cargos propuestos al rey por Varela, algunos aparecían «recomendados» por María Luisa de Parma:

78. A.H.N., Estado, leg.2858.

79. Godoy, Manuel: Memorias (ed. de Emilio La Parra y Elisabel Larriba), Alicante, Universidad de Alicante, 2008, I, caps. XVIII-XX, pp. 235-263.

80. Teófanes Egido defiende esta definición como la más correcta para definir la relación de Godoy con los reyes (EGIDO, op. cit.). 
«...no ha tenido a bien S.M. de tomar resolución alguna en punto a destinos; antes bien ha notado con sorpresa que en dichas listas se trata su Alta Persona como la de una particular, usándose en ellas la frase, recomendados por la Reina Nra Sra, nada correspondiente al decoro de la Majestad. La Reina Nra. Sra. no recomienda estando, como está, revestida de autoridad para mandar y disponer; SS.MM. previenen y entregan a sus Secretarios del Despacho que tengan presentes en sus propuestas los méritos de los sujetos que indican y por esto no han podido menos de extrañar y ver con desagrado una expresión tan irreverente como impropia» ${ }^{81}$.

Godoy dejaba bien claro que María Luisa no era una «particular», pues estaba «revestida de autoridad para mandar y disponer». El deseo de la reina no era una recomendación sino una orden; sus preferencias no eran deseos arbitrarios sino reflejos del mérito de los individuos. Tamaña ofensa merecía que se suspendiese «desde luego en su empleo al sujeto que haya extendido dichas listas, sea quien fuere». El Príncipe de la Paz protestaba también por haber visto su nombre en las listas, pero por todo lo contrario, él no nombraba ni recomendaba a nadie, sino los reyes:

«al mismo tiempo no puedo menos de manifestar a V.E. por mi parte que he visto en dichas listas mezclado entre otros mi nombre, lo que me ha sido muy sensible; pues si alguna vez he pasado a V.E. memoriales acompañados de oficios, ha sido por habérmelos entregado SS.MM. y en cumplimiento de mi empleo y cuando los sujetos han tenido relación con la vía de Estado de mi cargo he dado noticia de sus méritos contraídos en ella (...) para que por la misma se hiciesen presentes a SS.MM. dirigiendo yo mismo mis súplicas a SS.RR. Pies en los casos en que me ha interesado, decididamente en los cuales he experimentado las Bondades de Su R1. Benevolencia» ${ }^{82}$.

Varela respondió afligido al día siguiente, pidiendo perdón por la «impropia frase». El secretario protegía a su oficial mayor, y se arrepentía de «haber entregado a S.M. la Reina una lista formada sólo para mi reservado gobierno y concebida sin el decoro correspondiente a su augusta dignidad». «En tan melancólico accidente [escribía] ¿a quién hemos de acudir sino al generoso corazón de la Reina por la poderosa intercesión de V.E.?» ${ }^{83}$.

A vuelta de correo, Manuel Godoy volvía a referirse a la «expresión irreverente», señalando la diferencia entre recomendación «de la Reina Nra Sra o determinación de S.M. para que les atendiere según sus méritos» y advirtiendo que «semejantes equivocaciones y frases mal aplicadas socavan y atentan la autoridad Suprema y deben huirse con el mayor cuidado». «Bien segura de que no se repetirá más» el error, la reina ordenaba benignamente «que se restituya en su empleo al sujeto que entendió en la formación de dichas listas» ${ }^{84}$.

Este no es, ni mucho menos, el único ejemplo que tenemos del patronazgo directo de María Luisa. En el expediente del nombramiento como oficial de la secretaría de

81. El príncipe de la Paz a Varela. 14 de diciembre de 1796. A.H.N., Estado, 1.4834.

82. Ibidem.

83. Varela al príncipe de la Paz. San Lorenzo, 15 de diciembre de 1796. A.H.N., Estado, 1.4834.

84. El príncipe de la Paz a Varela. 16 de diciembre de 1796. A.H.N., Estado, 1.4834. 
Estado de Pedro Gómez Labrador (quien tendría una importante carrera diplomática en este reinado y el siguiente), el conde de Aranda especificaba que «es el que la reina indicó y lo afianza el gobernador del Consejo» ${ }^{85}$; en otras palabras: indicación de María Luisa y beneplácito del conde de la Cañada, uso de la Cámara de Castilla y de Gracia y Justicia hasta el control definitivo de las secretarías.

J.L Castellano - por cuyo libro tuve conocimiento del «desliz» de Pedro Varelapregunta con razón: «¿quién es ella para ejercer el derecho de gracia, el atributo de la soberanía que por su propia naturaleza es indelegable?» ${ }^{86}$. La respuesta a esta pregunta retórica -que lleva implícita un «nadie»- no es fácil. María Luisa era la reina de España, eso está claro, pero era reina consorte, la soberanía residía en su marido; ella, en principio, era «sólo» mujer y madre de reyes.

Pero la figura de la esposa del rey ya no era la de los tiempos de los Habsburgo. La llegada de los Borbones a España hizo cobrar importancia a la figura de la consorte real. Isabel de Farnesio y Bárbara de Braganza aparecían en el primer plano de la política de sus respectivos maridos, y sólo la viudez de Carlos III rompió el proceso que recuperaría la reina María Luisa. Las reinas consortes del XVIII, y no sólo en España, tuvieron un protagonismo político que no puede circunscribirse a una epidemia de abulia de sus maridos, tiene que haber algo más, y lo hay; hablaremos de ello en el próximo apartado.

\section{CARLOS IV, EL REY ABSOLUTO EN LA SOMBRA (REFLEXIONES FINALES)}

Los reyes borbónicos, padres de sus vasallos, explotaron la representación de su propia familia; de ahí, por ejemplo, la novedad que los retratos de familia firmados por Van Loo y por Goya suponen para la iconografía regia española ${ }^{87}$. Desde Isabel de Farnesio, las consortes españolas del XVIII vieron incrementado su protagonismo político. El secretario de Estado lo era también de la reina; lo fueron Godoy y Cevallos como lo había sido, por ejemplo, Ensenada ${ }^{88}$. Al patronazgo artístico y cultural ${ }^{89}, \mathrm{y}$ a una creciente presencia en la propaganda oficial ${ }^{90}$, las consortes de la Monarquía Hispánica dieciochesca unieron una mayor participación en las decisiones políticas.

Recurrentemente, se ha achacado a la debilidad mental de Felipe V y Fernando VI el protagonismo de sus mujeres, pero no se puede decir lo mismo en absoluto de Carlos IV. Muy lejos de lo que se piensa, los testimonios contemporáneos hablan de él como

85. LA PARRA, op. cit, p. 487.

86. CASTEllano, op. cit., p. 261.

87. SANCHO GASPAR, José Luis: La monarquía española en la pintura: los Borbones, Barcelona, 2005.

88. CAstellano, op. cit., p. 146.

89. No olvidemos que la reina era, igual que la Virgen María con Dios, intercesora y mediadora de los súbditos con el rey. Muchos memoriales políticos, como el de Malaspina, iban dirigidos a la soberana.

90. La consorte de Carlos IV fue, más que ninguna otra, retratada y ensalzada. La Junta de Damas la llamaba en sus elogios anuales «madre de sus vasallos» y «soberana». Los poemas y dedicatorias en su honor no se quedan atrás, tampoco los numerosos retratos. 
una persona testaruda y con carácter ${ }^{91}$; ¿cómo compaginar esta imagen con la que ha imperado durante dos siglos?

El poder de María Luisa era grande, pero sobre todo como prolongación del rey en la Corte. Si la reina mandaba, tenía que ser con el plácet último de la firma: «Yo el Rey». En mi opinión, el partido de la reina es el partido del rey. El uso del patronazgo regio no era una novedad ni mucho menos, aunque es posible que Carlos IV lo llevase a sus últimas y dramáticas consecuencias:

«Debido al carácter «compuesto» de la monarquía, menos centralizada y absoluta de lo que suele presentar, en una coyuntura especial como esta se veía obligado a imponer su propia red clientelar a las otras y la única forma de conseguirlo era a través del gobierno, la designación de cargos y la concesión de gracias y mercedes. Es decir, para implantar su autoridad el rey estaba obligado - de acuerdo con una idea de Elliott referida a otra época, pero igualmente válida para el final del siglo XVIII- a manipular en beneficio de la corona el sistema de relaciones sociales articulado por lealtades familiares y personales (...) Se trataba, en suma, de crear un elite de recomendados (en el sentido más directo del término) al servicio de la corona $»^{92}$.

Según esta necesidad de gobernar con gente de confianza hay que entender la figura de Godoy y sus palabras a María Luisa:

«Señora $(. .$.$) deben pues los reyes ser económicos en sus distinciones y tratos, no oír$ sino conductos puros y no comprometerse al acceso de personas malas como por desgracia sucede en las Cortes; el hombre está expuesto a oír más malo que bueno si se libra a la sociedad de los hombres y los reyes sin excepción no pueden oír nada bueno sino por su mujeres o íntimos amigos, raros son y son raras pero uno y otro puede reunirse, el rey tiene la fortuna de poseer una buena mujer pues mendigar noticias de otras personas ni menos oírlas por las contingencias que he dicho arriba» ${ }^{93}$.

La cita de La Parra en este sentido es impecable:

«El ascenso al poder de Godoy al poder político queda explicado, en suma, por la aplicación del procedimiento seguido por la monarquía del Antiguo Régimen en los momentos especialmente críticos. El rey «regalaba» poder a un servidor fiel para que este, haciendo uso a su vez de dádivas y recomendaciones, comprometiera a otros a sustentar el poder real. De esta manera la corte se convertía en el centro de una cultura del regalo -afirma Elliott- en que los límites entre reciprocidad en los favores, por una parte, y la corrupción, por otra, no eran definibles. Quienes quedaban despechados o excluidos de las gracias fácilmente podían considerar que todo era corrupción e intriga, notas que había que elevar al máximo si recaían en modo superlativo en una persona $»^{94}$.

En muchos casos, el rey se mantuvo al margen en apariencia y dejó que fuese la reina la que contactase con algún político o embajador. Carlos casi nunca demostraba preferencias, y dejaba que fuesen su consorte y su amigo Manuel quienes gestionasen

91. Fue Carlos quien se presentó en las habitaciones de Fernando en 1807, y fue también él quien quiso juzgarle, y no María Luisa.

92. LA PARRA, op. cit., pp. 99-100.

93. Godoy a María Luisa. 25 de Marzo de 1800 (PEREYRA, op. cit., pp. 274-275).

94. LA PARRA, op. cit., p. 100 
decisiones que ya habían sido tomadas previamente entre los tres, pero sobre todo por él, que era el monarca y quien tenía la última palabra. Resulta difícil saber si la pareja real estaba en desacuerdo en algún asunto político importante, pero sería de extrañar que esto ocurriera a menudo en un matrimonio regio tan unido desde la adolescencia. En medio de rumores, polémicas e intrigas, con la reina María Luisa y Godoy como cabeza visible, Carlos IV consiguió desarticular la herencia política de su padre en menos de un lustro, buscando crearse una red cortesana y administrativa afín. Es por esta motivación y no por puro capricho por lo que la pareja real actuó como hemos visto.

María Luisa era un instrumento político de su marido, alguien que podía inmiscuirse en los asuntos de la Corte sin que la figura del rey quedase dañada. En lances como el cese de Floridablanca, Carlos IV se lavó las manos, cobrando distancia una vez más de las intrigas de palacio. Fue Acuña, uno de los hombres de confianza de Godoy y su protectora quien llamó a Aranda a entrevistarse con María Luisa, lo que hace pensar a Egido que ella «reinaba de verdad» ${ }^{95}$. La reina tenía un papel importante en la Corte, pero haciendo el «trabajo sucio» del rey, que buscaba mantener su majestad sin inmiscuirse directamente.

Se podría pensar que, si esto es así, Carlos IV -destronado en 1808- se equivocó, lo que no es del todo cierto. Aquel rey llevó hasta el extremo el absolutismo de su padre, dejó de lado la Corte y reprimió a los Consejos ${ }^{96}$. Su despotismo le llevó a colmar de honores a un guardia de Corps ${ }^{97}$, nombrándolo Príncipe (aunque de la Paz) y poniéndolo al frente de la Monarquía. Maquiavélicamente utilizó a los arandistas para desplazar a los golillas de Floridablanca y así acabar a la postre con ambos grupos. A pesar de todo, aún hoy se piensa que la cara bondadosa de Carlos IV en los cuadros de Goya era una plasmación de la simpleza del monarca y no la imagen que un soberano de aquella época quería transmitir. Aquel rey quedó tanto para sus vasallos como para la posteridad como el estereotipo de «buen hombre», un rey con buenas intenciones

95. EGIDO, op. cit., p. 62.

96. Carlos III había respetado la Corte como centro de poder (de quien Fernán Núñez dijo que eran tan ceremonioso que se podía saber lo que estaba haciendo en cada momento) y se había mostrado más cauto a la hora de saltarse ciertos procedimientos en la distribución de gracias: «casi siempre Carlos III, al contrario de lo que pasará en el reinado de su sucesor, nombra tendiendo en cuenta la consulta de la Cámara; pocas veces lo hace sin mediar esta» (CASTELLANO, op. cit., pp. 229-230). Carlos IV toma medidas «para debilitar el régimen de los Consejos en su conjunto», extendiendo los honores para ganar adeptos y a la par disminuir la importancia de dichos honores, y por otro lado, insistimos, nombrando «por decreto, sin mediar consulta de la Cámara o de cualquier otro organismo» (Ibidem, pp. 258-259).

97. Si Floridablanca, un hombre de carrera, sintió el recelo de los privilegiados, el rechazo al Príncipe de la Paz fue extremo. Godoy suponía la vulneración total del concepto de mérito. El poder de Carlos IV era absoluto, pero hasta cierto punto, así que la confianza personal debía materializarse en una serie de honores que, por su profusión y su evidente origen en el capricho regio, humillaban por asimilación al resto de los nobles. Ser Grande de España significaba poco si también lo era Godoy. Años de carrera en una secretaría quedaban vulnerados si el patronazgo regio se saltaba todos los turnos. La figura de Godoy removía todas las bases políticas que equilibraban la monarquía hispánica. Carlos IV no fue un rey débil, sino el más autoritario del Antiguo Régimen español; pensó que podía gobernar a su antojo y se equivocó. 
preso del mal gobierno de su mujer y su valido. $\mathrm{Si}$, por el contrario, pensamos que $\mathrm{M}^{\mathrm{a}}$ Luisa y Godoy no fueron más que las caras visibles de su soberanía, quizá podamos pensar que lo hizo «demasiado bien» (lo que no deja de ser una propuesta interpretativa).

El «partido de la reina», heterogéneo políticamente en sus inicios, tenía una intención que lo aglutinaba: barrer a la clientela de Floridablanca; pero en el futuro la política interior y exterior lo disgregará en varios grupos. Godoy siguió unido personalmente a sus protectores, pero continuando por otra parte la política reformista que caracterizó su gobierno de finales de siglo. María Luisa era más proclive a posturas más conservadoras y cercanas a la ortodoxia católica y al «antijansenismo».

Godoy despertó el odio de la Corte y no necesariamente por su gran poder. Es muy posible que Floridablanca hubiera tenido mayor capacidad de decisión sobre los asuntos de Estado que el extremeño (Carlos IV y M M $^{\mathrm{a}}$ Luisa controlaban bastante más a «su hechura» Godoy, que Carlos III a Moñino). Esta afirmación me parece evidente a partir de 1798, cuando Godoy desapareció de las secretarías (dirigiendo la carta de su supuesta dimisión a la reina, por cierto). A su regreso como Generalísimo, los reyes habían confiado en dos personajes que pronto se convirtieron en sus enemigos, me refiero a Cevallos y a Caballero ${ }^{98}$. El primero, secretario de Estado, el segundo de Gracia y Justicia. Desde ese momento, el partido de la reina (que es, insisto, el del rey) y el de Godoy, se separaron. El príncipe de la Paz observó que los reyes desoían muchos de sus consejos (esta no es una afirmación derivada de una fe ciega en las Memorias del Príncipe de la Paz, hay constancia epistolar, por ejemplo, de sus fallidas intercesiones por Jovellanos, preso en Bellver ${ }^{99}$ ).

El «amigo Manuel» y su clientela fueron uno más de los grupos en los que se apoyaron los reyes para gobernar una vez tomaron el control de la Corte. Es entonces (a partir de 1797-1798) cuando la línea política de Carlos IV es más difícil de delimitar, puesto que en la última década de su reinado coincidieron decisiones y nombramientos de tendencia contradictoria. Por lo que sabemos -o suponemos- de María Luisa de Parma, es difícil explicar que aceptase las decisiones del gabinete «ilustrado» o «jansenista». ¿Fue por tanto Urquijo un protegido del rey?, ¿era Carlos IV más progresista

98. Caballero (y de nuevo me salgo brevemente del marco cronológico del trabajo), ha sido considerado tradicionalmente una prolongación del poder de la Reina. Desde luego, su control sobre el patronazgo cortesano fue tremendo, pero una vez más creo más acertado unir a este ministro a los intereses de Carlos

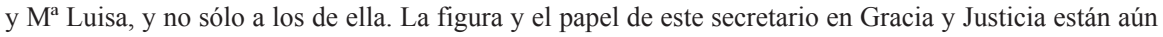
por estudiar; su presencia parece una reacción al gabinete «ilustrado» por parte de la pareja real. En sus Memorias, el Príncipe de la Paz le achaca gran número de decisiones (las menos populares) y le concede un gran ascendiente sobre los reyes. Muriel observó esta actitud en Godoy, pero reconocía la influencia de Caballero, a quien consideraba un instrumento de $\mathrm{M}^{\mathrm{a}}$ Luisa (MURIEL, op. cit., II, p. 50).

99. En la correspondencia de Godoy con los reyes, se puede ver la negativa de ambos a perdonar a Jovellanos a pesar de la solicitud del Príncipe de la Paz: «Veo lo que nos dices en el asunto de Jovellanos: a la vista hablaremos, Manuel, pero no estamos acordes con eso...» (SECO SERRANO, Carlos: "Godoy y Jovellanos», en LA PARRA LÓPEZ, Emilio y JimÉnEZ, Miguel Ángel -coords.-: Manuel Godoy y la Ilustración. pp. 51-62). 
que su esposa? Si la respuesta a estas preguntas es afirmativa, el poder absoluto de la reina no era tal; si la respuesta es negativa, y todas las decisiones del rey eran consensuadas con su esposa, el papel de $\mathrm{M}^{\mathrm{a}}$ Luisa y la Santa Sede en la caída de Urquijo, sería infundado.

Obviamente, el papel de la parmesana en la Corte de Carlos IV y muchas otras reflexiones aquí planteadas (las masivas creaciones de títulos nobiliarios tras la proclamación de Carlos IV, las labores de Acuña, Llaguno, Jovellanos o Caballero en Gracia y Justicia, el estudio del perfil político de todos estos hombres, y un largo etcétera) requieren un estudio más amplio que está en curso; estos son sus primeros pasos, siempre abiertos a sugerencias y al debate ${ }^{100}$. 